\title{
Self-Forgiveness and Life Satisfaction in People Living with HIV/AIDS
}

\author{
Mudgal, S. ${ }^{1 *}$, Tiwari, G. K. ${ }^{2}$
}

\section{ABSTRACT}

The basic goals of the present study were to explore the nature and patterns of relationship between self-forgiveness and life satisfaction of the participants diagnosed with HIV/AIDS and normal healthy persons with no reported chronic physical and/or mental health problems. A total of eighty participants comprising forty diagnosed HIV/AIDS adult patients aged 30 to 42 years $(M=35.50, S D=4.77)$ and forty normal individuals aged 19 to 40 years $(M=26.81, S D=4.79)$ took part in the study whose self-forgiveness and life satisfaction were measured through standardized psychometric tools. The results of the present study demonstrated that the participants inflicted with HIV/AIDS had lower mean self-forgiveness score as compared to their normal counterparts. The same trend was found to be recurring again for the life satisfaction scores of HIV/AIDS and normal participants. The results of the study have been discussed in the light of current theoretical background of forgiveness, life satisfaction and chronic disease. The findings of the study have important implications for policy makers, health professionals, caregivers, students, researchers and administrators.

Keywords: Self-forgiveness, Forgiveness, Life satisfaction, HIV/AID, Chronic illness.

Forgiveness has become a popular topic of increasing interest to the researchers in the recent past. The researchers have laid emphasis on the multidimensional nature of forgiveness and the importance of both interpersonal as well as self-forgiveness (Enright \& The Human Development Study Group, 1996), the self-forgiveness has still attracted comparatively little empirical attention. Most research programmes have tended to discuss the nature of selfforgiveness only within the context of interpersonal forgiveness theory (Tangney, Boone, \& Dearing, 2005), making efforts to draw parallels between forgiveness of self and forgiveness of others. The researches have demonstrated that self-forgiveness is only weakly correlated, and in some studies unrelated to forgiveness of others (Mauger, Perry, Freeman, Grove, McBride, \& McKinney, 1992; Thompson, Snyder, Hoffman, Michael, Rasmussen, Billings, Heinze, Neufeld,

\footnotetext{
${ }^{1}$ Research Scholar, Department of Psychology, School of Humanities \& Social Sciences, Doctor Harisingh Gour Vishwavidyalaya, Sagar

${ }^{2}$ Assistant Professor, Department of Psychology, School of Humanities \& Social Sciences, Doctor Harisingh Gour Vishwavidyalaya, Sagar

*Responding Author

(C) 2015 I S Mudgal, Tiwari G; licensee IJIP. This is an Open Access Research distributed under the terms of the Creative Commons Attribution License (http://creativecommons.org/licenses/by/2.0), which permits unrestricted use, distribution, and reproduction in any Medium, provided the original work is properly cited.
} 
Shorey, Roberts, \& Roberts, 2005), suggesting a need for more focused study on the nature of self-forgiveness.

With the beginning, self-forgiveness has been conceptualized as a process in which offenders choose to acknowledge one's own responsibility for wrongdoing while also retaining one's personal worth given one's inherent ability to learn from past mistakes (Berecz, 1998; Enright et al., 1996). These definitions are heuristic in nature as they depict the process of self-forgiveness unfolding over time and lack the empirical foundation necessary to inspire researchers. Contrarily, Hall and Fincham (2005) defined self-forgiveness as a motivational shift in which one's desires to avoid offense-related stimuli and to retaliate against oneself decrease while one's desire to act benevolently toward oneself increases. They described self-forgiveness as a process maintaining that perpetrators may vacillate between self-condemning and self-forgiving motivations. They further suggested that emotional correlates (guilt, shame, and empathy), social-cognitive correlates (attributions of blame regarding an offense and perceived forgiveness), behavioral correlates (conciliatory behavior), and offense-related correlates (perceived transgression severity) influence the likelihood that a person will self-forgive.

The present research aims to explore the nature and relationship of self-forgiveness and life satisfaction of the participants suffering from human immunodeficiency virus (HIV) which causes the acquisition of immune deficiency syndrome (AIDS) occurring in Indian socio-cultural context. The HIV/AIDS epidemic constitutes an unprecedented biopsychosocial phenomenon impacting not only health but also all aspects of life for the persons living with HIV/AIDS, including marriage and intimate relations, childbearing and parenthood, work and social functioning, as well as psychological and spiritual well-being (Temoshok, 1990, 1998). As health status situation, HIV/AIDS provides perhaps the quintessential paradigm for studying the impact of self-forgiveness on life satisfaction. It may be argued that perceptions of HIV/AIDS are much like perceptions of cancer long ago: a usually fatal, essentially incurable disease associated with stigma and a sense of hopelessness. Unlike cancer, however, HIV is an infectious disease, transmissible by two of the most intrinsic human forces-sexuality and procreation. The intense fear and stigma surrounding transmission in these most intimate of human connections have put the multidimensional concept of self-forgiveness in a central role for those living with HIV/AIDS. How do HIV-infected men and women come to terms with the natural desires to give life and to see life continued through their children, and the realistic fear that their children may be born infected with HIV, or if spared that fate, may become orphans at young age (Goldschmidt, Temoshok, \& Brown, 1993)? This is the basic question the present study will try to answer. The present research attempted to develop an understanding of the role played by HIV/AIDS disease in accruing the nature and extent of relationships between self-forgiveness and life satisfaction of the participants. 


\section{Hypotheses}

On the basis of review of literature, the following hypotheses have been formulated to be tested through the findings of the present study:

1. The mean self-forgiveness score of the non-clinical participants will show significant difference with the mean score on the same measure of the clinical participants.

2. The mean life satisfaction score of the non-clinical participants will be higher as compared to the clinical counterparts.

\section{METHODS AND PROCEDURE}

\section{Sample}

Forty diagnosed HIV/AIDS patients registered in Antiretroviral Therapy (ART) Center Bundelkhand Medical College, Sagar, M. P. comprising twenty seven males $(\mathrm{M}=35.63$, SD = 4.58) and thirteen females $(M=33.69, \mathrm{SD}=3.57)$ and forty postgraduate students from Doctor Harisingh Gour University Sagar, Madhya Pradesh, India comprising twenty eight male $(\mathrm{M}=$ 28.00, $\mathrm{SD}=4.78)$ and twelve females $(\mathrm{M}=24.17$, $\mathrm{SD}=5.99)$ served as the participants in the study. The age range of the participants was from 19-42 years. They belonged to different socioeconomic backgrounds mostly associated with lower middle class Hindu family.

\section{Tools}

Two psychometric tools were used in the study with which the self-forgiveness and life satisfaction of the participants have been measured. The short descriptions of the tools are as follows:

\section{a. Heartland Forgiveness Scale (HFS)}

The participant's self-forgiving attitude was assessed using translated version of The Heartland Forgiveness Scale (Thompson et al., 2005). The scale was first translated into Hindi and retranslated into English before being administered for actual data collection. The Heartland Forgiveness Scale consists of 18 items, with three subscales consisting six-items each assessing forgiveness of self, others, and situations. Only the subset of six items meant for self-forgiveness was used in this study. Each item comprised seven-point Likert scale ( 1 = Almost always false of me; 7 = Almost always true of me). The participants were instructed to think about how they have responded to themselves when they have done something wrong. The wording of the items were generally in the direction of higher scores meaning more self-forgiveness, (e.g. With time I am understanding of myself for mistakes I've made and Learning from bad things I've done helps me get over them), and three of these items were reverse-scored so that a higher total score would indicate greater self-forgiveness. The Cronbach's alpha was reported to be .805 .

\section{b. The Life satisfaction scale}

The level of life satisfaction of the participants was assessed by using life satisfaction scale (Alam \& Srivastava, 2001). The scale comprises of 60 items with the alternatives of Yes and No involving the six areas of life viz. Health, Personal, Economic, Marital, Social and occupational. Yes response indicated satisfaction, whereas No signified dissatisfaction with life. Every 'Yes' 
response was assigned 1 whereas 'No' was scored as 0 . The sum of the scores was obtained for the entire scale. The test-retest reliability of the scale was found to be .84 .

\section{Procedure}

As per the requirement of the study, data were collected from two different sources. The data of 40 people living with HIV/AIDS were collected from Bundelkhand Medical College, Sagar, M. P. with the permission of the Nodal officer of ART center whereas normal participants from Doctor Harisingh Gour Vishwavidyalaya, Sagar, M. P. with no physical/mental health problems were the other source of data. The instructions were made clear orally to them first before they were supplied with the questionnaires and requested to answer each item carefully as per the directions written in the beginning of each scale. The participants were informed that participation was voluntary and responses will be kept confidential. Their written consents were collected before they actually started to answer the items of the questionnaires of the study. The average length of time needed to complete the questionnaires was approximately 20 minutes.

\section{RESULTS}

The results revealed that the clinical participants exhibited lower mean score (Mean $=24.35$, SD $=4.96$ ) on self-forgiveness measure as compared to the non-clinical participants (Mean=29.18, $\mathrm{SD}=2.60$ ). In the same manner, the clinical group showed similar performance in evoking lower mean score $($ Mean $=38.50, \mathrm{SD}=2.60)$ on life satisfaction measure as compared to the normal healthy (Mean $=44.25$, SD $=3.33$ ).

Table 1: Mean self-forgiveness and life satisfaction scores of clinical and non-clinical participants

\begin{tabular}{|c|c|c|c|c|c|}
\hline S. No. & Participants & Measures & Mean & SD & N \\
\hline \multirow{2}{*}{1.} & \multirow{2}{*}{ HIV/AIDS } & Self-forgiveness & 24.35 & 4.96 & 40 \\
\cline { 3 - 6 } & & Life satisfaction & 38.50 & 4.80 & 40 \\
\hline \multirow{2}{*}{2.} & \multirow{2}{*}{ Normal } & Self-forgiveness & 29.18 & 2.60 & 40 \\
\cline { 3 - 6 } & & Life satisfaction & 44.25 & 3.33 & 40 \\
\hline
\end{tabular}

The mean scores on self-forgiveness $(\mathrm{t}=5.23$, $\mathrm{df}=39, \mathrm{p}>.001)$ and life satisfaction $(\mathrm{t}=6.19$, $\mathrm{df}$ $=39, \mathrm{p}>.001)$ of the clinical and non-clinical participants showed statistically significant difference. 


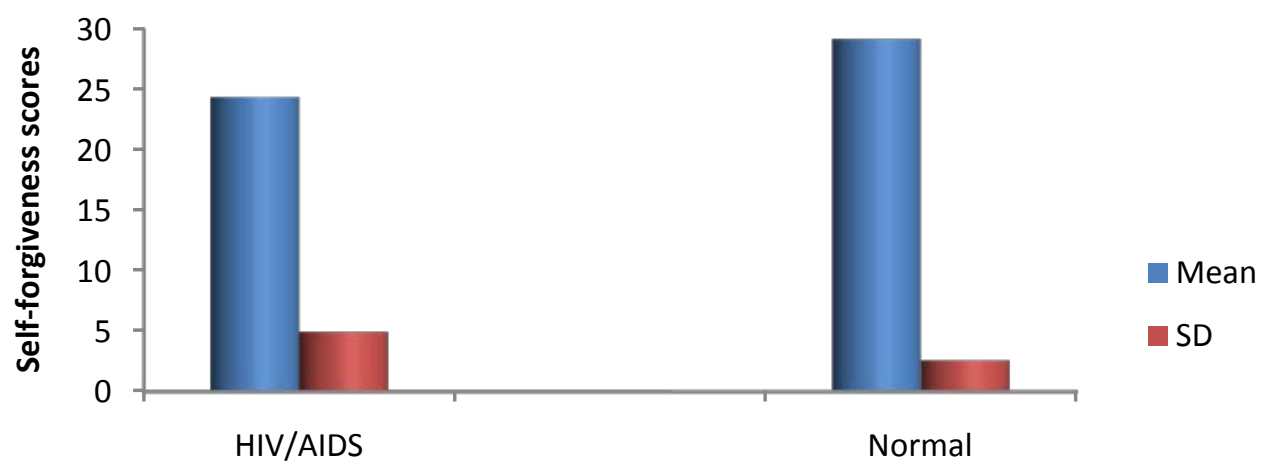

Figure 1: Mean self-forgiveness scores of HIV/AIDS patients and normal participants

Thus, there was a significant difference on the level of self-forgiveness among HIV/AIDS patients and their normal counterparts. Analysis of life satisfaction score also showed the same trend. These results have been presented in table 1 and Figures 1 and 2.

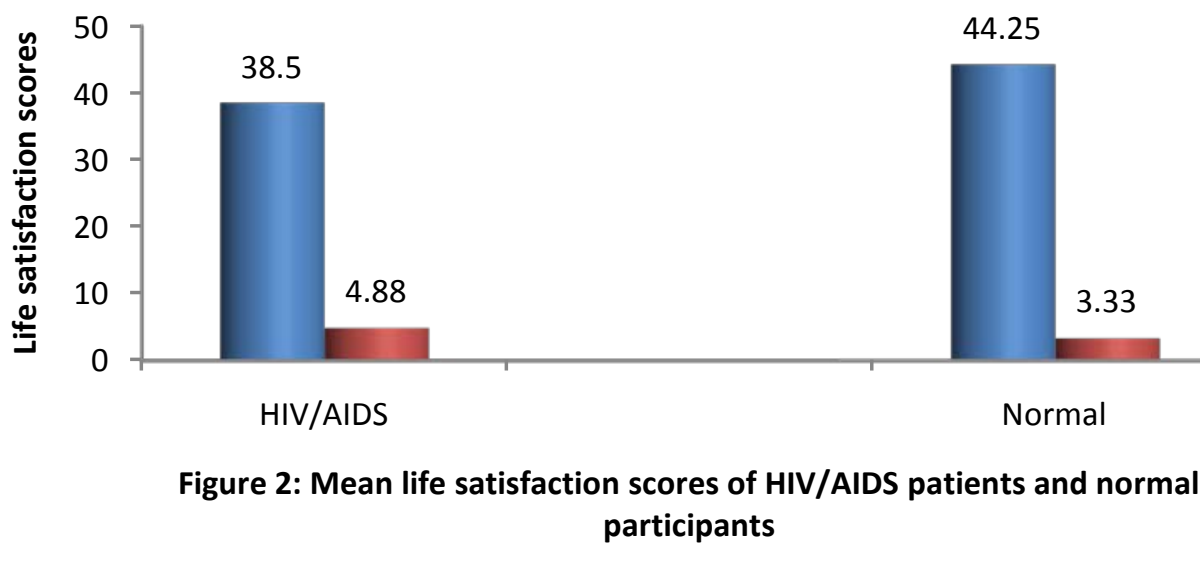

\section{DISCUSSION}

The results of the study made it evident that nature of self-forgiveness and life satisfaction of people living with HIV/AIDS and the normal participants were shaped by the fact that whether they were inflicted by the chronic disease of HIV/AIDS or not. The chronic illness like HIV/AIDS has a major impact on various aspects of the patient's life. The results of the study showed that HIV/AIDS patients emitted lower level of mean self-forgiveness score as compared to normal people resulting into the confirmation of first hypothesis of the study. Second hypothesis also got approved as HIV/AIDS patients evoked lower mean score on life satisfaction measure as compared to the normal participants. The values of t-test evinced that the mean scores on these two measures achieved by the two groups of participants were statistically significant. 
The HIV/AIDS patients have many reasons of being affected with this kind of chronic illness but irrespective of reason being HIV positive is really a taboo in Indian society. There are plenty of societal and emotional harassments have to be faced by the HIV/AIDS patients and in this condition it is very difficult to forgive another person who is responsible for such condition as well themselves for having followed along with their decisions consequent of which it turned into a fatal disease like HIV/AIDS. While determining the reasons behind self unforgiving state, self blaming, guilt and shame play an important role. When a person feels guilt and starts blaming himself/herself, it becomes very difficult for him/her to forgive the self because once feeling of self blame occur our ego-defense mechanisms almost stop working.

The mean life satisfaction score of HIV/AIDS patients were found to be lower because the long duration of chronic disease might have made the patients prone to suffer stress (Godsoe, 2008). In general, chronic diseases have multiple impacts on the psychological functioning of the patients. Chronic disease of HIV/AIDS has been reported to affect perceptions of body image and has resulted into reduced body image satisfaction/life satisfaction (Jain \& Tiwari, in press) and self-esteem (Tiwari, 2014; Tiwari \& Kumar, 2015) of the participants. Moreover, the HIV/AIDS has also been found to affect emotion regulation processes and caused inappropriate application of emotion regulation strategies viz., emotional suppression and cognitive reappraisal on the part of the participants (Tiwari, 2015). The people with chronic diseases may become more sensitive, making it more easily offended than those with normal health (Godsoe, 2008). The Chronic disease patients may also have problems in their interpersonal relationships and self-concept (Tiwari, 2014). Morrison and Bennett (2009) reported that the inability of patients with chronic diseases in expressing their complaint to the others can make them feel upset and non-understandable. This condition can certainly cause discomfort and result into interpersonal conflicts. The pain they feel can also hamper and disturb their daily functioning. For example, patients with lower back pain typically will experience a decline in cognitive performance (Weiner, Rudy, Morrow, Slaboda, \& Lieber, 2006). This condition can affect the patient's ability to manage information for daily functioning. Psychologically, this can also lead the patients to feel depressed, anxious, and hopeless to face their chronic diseases. In general, the individuals with chronic diseases like HIV/AIDS experience a decline on satisfaction with their life (Jain \& Tiwari, in press; Nowakowski, 2014). Usually, such person will also will experience a change in their daily activities as a results of physical impairment caused by chronic disease. However, the

people with chronic disease often face a more complex situation than the normal people. They tend to undergo more and more medical treatment and spend more money for it (Zulman, Asch, Martins, Kerr, Hoffman, Goldstein, 2013). In addition, multiple chronic diseases deteriorate the physical condition of the elderly so their daily activities also become more limited (Schilling, Wahl, \& Oswald, 2013) and affects the patient's ability to work (Zulman et al. 2013). Physical impairment experienced due to this condition also lowers patient's psychological functioning (Schilling \& Wahl, 2006). 


\section{CONCLUSIONS AND SUGGESTIONS FOR FUTURE RESEARCH}

It can be concluded from the findings of the study that people living with HIV/AIDS have lowered level of self-forgiveness and life satisfaction as compared to the normal healthy participants. The HIV/AIDS patients showed lower mean scores on self-forgiveness as well on life satisfaction as compared to their normal counterparts. It is expected that self-forgiveness based psychotherapeutic intervention techniques would do well in the case of people suffering from HIV/AIDS. A very small sample, limited geographical area and selection of only two variables constitute some of the limitations of this study. The future researches may be conducted comprising relatively a large sample with varying socio-cultural attributes and with multiple variables. Another suggestion for future research is that they should involve qualitative methods as the questionnaires did not provide them with a sufficient opportunity to express themselves. The results and conclusions of the study have important implications for future researchers, planners, policy makers and health professionals who are associated with the services of people inflicted with chronic disease like HIV/AIDS.

\section{Acknowledgement}

The authors wish to acknowledge to Dr. Abhay Tirkey, Nodal Officer, ART center Bundelkhand Medical College, Sagar, M. P., National AIDS Control Organization (NACO), India for permitting us to collect the data on HIV/AIDS patients, Mr. Anupam Bohre, Senior Counsellor, for his supervision and cooperation during the data collection and Dr. Shikha Agrawal, Medical Officer, for her great support, help, and giving us appropriate knowledge about the disease and treatment. I am thankful to the Department of Psychology, Doctor Harisingh Gour University, Sagar, M. P. for permitting and encouraging us to conduct and carry out of study. We are also thankful to Mr. Pankaj Jain, Research Scholar, Department of Psychology, School of Humanities \& Social Sciences, Doctor Harisingh Gour Vishwavidyalaya, Sagar, M. P. for extending his cooperation and help in data collection and compilation.

\section{REFERENCES}

Alam, Q. G. \& Srivastava, R. (2001). Life satisfaction scale. National Psychological Corporation, Agra, India.

Berecz, J. M. (1998). Beyond shame and pain: Forgiving yourself and others. Lima, OH: CSS

Enright, R. D., \& The Human Development Study Group (1996). Counseling within the forgiveness triad: On forgiving, receiving forgiveness, and self-forgiveness. Counseling and Values, 40, 107-126.

Godsoe, M. R. (2008). Acceptance of chronic pain, attachment style, affectivity and treatment use. New Hampshire: Antioch University New England.

Goldschmidt, M., Temoshok, L., \& Brown, G. R. (1993). Women and HIV/AIDS: Challenging a growing threat. In C. A. Niven \& D. Carroll (Eds.), The health psychology of women (pp. 91-106). London Harwood Academic Press.

Hall, J. H. \& Fincham, F. D. (2005). Self-forgiveness: The stepchild of forgiveness research. Journal of Social and Clinical Psychology, 24, 621- 637.

Jain, P. \& Tiwari, G. K. (in press). Body image satisfaction and life satisfaction in HIV/AIDS patients. The International Journal of Indian Psychology. 
Mauger, P.A., Perry, J. E., Freeman, T., Grove, D. C., McBride, A.G., \& McKinney, K. E. (1992). The measurement of forgiveness: Preliminary research. Journal of Psychology and Christianity,11,170-180.

Morrison, V. \& Bennett, P. (2009). An Introduction to Health Psychology (2nd ed.). Spain: Pearson Education Limited.

Nowakowski, A. C. H. (2014). Chronic inflammation and quality of life in older adults: a crosssectional study using biomakers to predict emotional and relational outcomes. Health and Quality of Life Outcomes, 12(1), 141-153.

Schilling, O. K. \& Wahl, H. W. (2006). Modeling late life adaptation in affective well-being under a severe chronic health condition: The case of age-related macular degeneration. Psychology and Aging, 21, 703-714. doi: 10.1037/0882-7974.21.4.703

Schilling, O. K., Wahl, H. \& Oswald F. (2013). Change in life satisfaction under chronic physical multi-morbidity in advanced old age: potential and limits of adaptation. Journal of Happiness Studies, 14, 19-36.

Tangney, J. P., Boone, A. L., \& Dearing, R. L. (2005). Forgiving the self: Conceptual issues and empirical findings. In E. L., Worthington, Jr. $\quad$ (Ed.), Handbook of forgiveness (pp.143-158). New York: Routledge.

Temoshok, L. R. (1990). Applying the biopsychosocial model to research on HIV/AIDS. In B. Bennett, J. Weiman \& P. Spurgeon (Eds.), Current developments in health psychology, (pp. 129-158). London Harwood Academic Press.

Temoshok, L. R. (1998). HIV/AIDS. In H. S. Friedman (Eds.), Encyclopedia of mental health (Vol. 2, 375-392). San Diego: Academic Press.

Thompson, L. Y., Snyder, C. R., Hoffman, L., Michael, S. T., Billings, L. S., Heinze, L., Neufeld J. E., Shorey, H. S., Roberts, J. C., \& Roberts, $\quad$ D. $\quad$ E. $\quad$ (2005). Dispositional forgiveness of self, others, and situations. Journal of Personality, 2, 313-359.

Tiwari, G. K. \& Kumar, S. (2015). Psychology and body image: A review. SHODH PRERAK, 5, 1-9.

Tiwari, G. K. (2014). Body image satisfaction enhances self-esteem. VAICHARIKI, 4 (4), 7-11.

Tiwari, G. K. (2015). Chronic physical illness affects emotion regulation process: A case of HIV/AIDS. The International Journal of Indian Psychology, Volume 3, Issue 1, No. 8, 158-167. DIP: C03143V3I12015

Weiner, D. K., Rudy, T. E., Morrow, L., Slaboda, J., \& Lieber, S. (2006). The relationship between pain, neuropsychological performance, and physical function in community-dwelling older adults with chronic low back pain, Pain Medicine, 7 (1), 6070.

Zulman, D. M., Asch, S. M., Martins, S. B., Kerr, E. A., Hoffman, B. B., Goldstein, M. K. (2013). Quality of care for patients with multiple chronic conditions: the role of comorbidity interrelatedness. Journal of General Internal Medicine, 29 (3), 529-537. 